\title{
A filosofia enquanto crítica literária. O Baudelaire de Benjamin, e vice-versa
}

\author{
Bernardo Barros Coelho de Oliveira
}

\section{Crítica e reflexão românticas}

Há uma frase de Novalis que talvez seja a mais freqüentemente convidada a participar dos textos de Walter Benjamin. Ela aparece em pelo menos quatro de seus trabalhos. ${ }^{1} \mathrm{~A}$ frase diz que "Toda obra de arte tem um Ideal a priori - tem uma necessidade em si de estar âै"*. A sua recorrência é muito significativa, e nos arriscaríamos a dizer que ela poderia ser citada em praticamente qualquer dos ensaios benjaminianos. Sobretudo naqueles que fazem de uma obra de arte, em especial da literatura, tema privilegiado. Sua tese sobre a crítica de arte no primeiro romantismo pode nos dar pistas para saber por que a frase é importante.

Nesse livro, Walter Benjamin reúne, seleciona e às vezes quase modifica uma série de fragmentos de Friedrich Schlegel e Novalis, procurando dar forma a um assunto certamente importante entre os abordados por esses autores, mas não o único. Benjamin expõe o projeto de sua própria atitude de crítico por intermédio de sua leitura dos românticos. Certos postulados que Benjamin extrai da obra dos românticos podem nos ajudar a compreender o gesto filosófico desse pensador que posteriormente não escreveu nenhum tratado sobre a obra de arte em geral, mas apenas ensaios, longos ou curtos, sobre obras ou grupo de obras.

Em outro trecho de Novalis citado por Benjamin, lemos que "Recensão é complemento do livro. Alguns livros não precisam de recensão alguma, apenas de um anúncio; eles já contêm a recensão"* "Recensão" é o termo português, hoje em desuso, utilizado para traduzir o muito semelhante usado pe-

(Benjamin, Walter. O conceito de crítica de arte no romantismo alemão. São Paulo: lluminuras, 1993: 84).

${ }^{1}$ É citada pela primeira vez em 1915, no ensaio sobre "dois poemas de Hölderlin", depois em sua tese $O$ conceito de crítica de arte no romantismo alemão, reaparecendo em seu ensaio sobre Dostoievski e no livro sobre o drama barroco alemão. 
los românticos para designar, por exemplo, a famosa crítica de F. Schlegel sobre o romance Wilhelm Meister, de Goethe. Naquela "recensão" Schlegel afirmava que "Felizmente ele [o Meister] é precisamente um destes livros que julgam a si mesmos"*. Esta afirmação contém um princípio. Crítica vem do grego krínein, que significa isolar, separar, destacar o particular. ${ }^{2}$ Para os românticos de Iena, só merece ser criticado aquilo que já contém, em sua própria particularidade, um "germe crítico". Em outros termos, livros como o Meister de Goethe já sabem identificar a si próprios, já possuem uma clara noção da necessidade de estarem "aî", de seu "ideal $a$ priori", de sua diferença para com outras obras. Aparentemente, então, nada mais simples que o trabalho da crítica. Uma determinada frase da tese benjaminiana, caso citada isoladamente, parece confirmar essa pretensa simplicidade: "A crítica é, então, diante da obra de arte, o mesmo que a observação é diante do objeto natural"*. Mas o que é observar? O sentido dessa ação é desenvolvido no contexto da teoria romântica do conhecimento. Afinal, diz Benjamin, para a crítica "valem todas aquelas leis que existem no geral para todo conhecimento de objeto"*. Que leis são essas? Um fragmento de Novalis diz algo sobre observar um objeto natural: "Em todos os predicados nos quais nós vemos o fóssil, ele nos vê". Ao comentar esse fragmento, Benjamin diz: "Podese compreender adequadamente esta atenção sobre o observador apenas como um sintoma da capacidade das coisas de verem a si mesmas"**.

Mas o "fóssil" "nos vê" porque, de certo modo, vê a si mesmo. O nosso olhar sobre ele retoma este autoconhecimento em germe no próprio fóssil. Mais que medir essas afirmações com as réguas do bom senso, devemos aproveitar o que têm de mais proveitoso. Uma coisa, diz Benjamin, nada mais é que "uma forma inferior entre as infinitas formas do simesmo [...] Novalis não se cansou de afirmar esta dependência de todo conhecimento objetal com relação a um autoconhecimento do objeto"*. Muitas trilhas se abrem aqui. Para nós, todavia, o importante está em uma das conseqüências desse modelo de conhecimento, e que vem a ser justamente a

${ }^{2}$ Cf. Heidegger, Martin. Qu'est-ce qu'une chose?. Paris: Gallimard, 1987, p. 130. 
idéia de que a reflexão, iniciada em uma coisa, natural ou não, pode ser retomada para além dela, que o ver a si mesma de uma coisa pode se dar com mais intensidade quando reapropriada pelo ver a si mesma de outra, que o emissor do brilho não é o mais apto para perceber seu próprio reflexo com nitidez. Como a reflexão de uma coisa continua na outra, a realidade pode ser vista como uma rede de reflexões que se potenciam infinitamente. Isso evidencia, ao menos, que não é fácil recobrir a noção romântica de reflexão com a de pensamento representativo, pois no modelo cartesiano do pensamento que pensa a si mesmo, ou do Eu fichteano, movimentos fechados na dinâmica de auto-espelhamento, reside o primeiro grande ponto de discordância dos românticos com o pensamento moderno de sua época. Podemos tentar usar a própria noção de crítica como um esclarecimento parcial disso.

"Na medida em que a crítica é conhecimento da obra de arte, ela é o autoconhecimento desta"*, diz Benjamin. Se a crítica é "observação" da si-mesmidade da obra, ela não é nunca a relação de um sujeito que observa desde um "fora" qualquer o que se encontra pronto "dentro" do objeto artístico. O movimento, para ser reflexivo no sentido romântico, precisa ter direção inversa. A obra de arte revela, através da crítica, sua vocação para ser retomada e continuada para além de si mesma. "Para os românticos", diz Benjamin, "a crítica é muito menos o julgamento de uma obra do que o método de seu acabamento"*. Essa noção de acabamento deve ser perpassada pela de intensificação. Não se trata de acrescentar algumas peças que teriam faltado, mas sim de retomar, em outro registro, o discurso da obra sobre si mesma.

Uma objeção recorrente do nosso comum senso ao discurso crítico residiria justamente na constatação de que uma crítica é algo fundamentalmente diferente de um romance, por exemplo. Criticar uma poesia seria, então, algo como fazer mímica a respeito de uma música, ou dançar a propósito de um quadro. Essa concepção entende a obra como um texto original, e a crítica como uma derivação não essencial e arbitrária. A posição defendida por Benjamin em seu livro sobre Schlegel não vê na heterogeneidade formal entre crítica e texto poético uma objeção. Ao contrário. Nos termos de Schlegel, toda crítica, mesmo heterogênea, deve ser "poética". "Essa crítica poética $[\ldots .$.$] exporá novamente a exposição, desejará for-$ 
mar ainda uma vez o já formado [...], irá completar a obra, rejuvenescê-la, configurá-la novamente”* . Esta reconfiguração deve ser, do ponto de vista da si-mesmidade da obra, na condição de autoconhecimento dela, uma intensificação ou potenciação. A crítica legítima só acontece quando aquilo que a obra já consegue formular sobre si mesma é amplificado e desdobrado. Nessa transposição, perde-se justo aquilo que, em sua configuração original, constitui o irrepetivel da obra, a sua forma singular, aquela seqüência de palavras que - por exemplo, em As flores do mal - está sempre ali, intacta, pronta para ser repetida como num ritual, por um novo leitor que se apresente. O paradoxo reside no fato de que a si-mesmidade da obra está menos em afirmações de caráter teórico nela contidas que no caráter único da sua forma. A escolha da palavra certa, aquela que depois se mostra insubstituível, já é crítica.

A possibilidade da crítica, todavia, apóia-se em uma característica da obra de arte: justo por apresentar uma identidade tão marcante, ela é um artefato que faz o seu observador falar. Mais que qualquer coisa, a obra de arte contém uma provocação à sua auto-superação e continuação no discurso de quem a observa. Por isso, talvez ela seja a mais fértil determinação que a reflexão é capaz de assumir. Em outros termos, o que distingue maximamente a obra de arte é o fato de que ela, apesar ou justamente por sua rigidez e precisão formal (aquilo que tanto a individualiza, a ponto de, por si mesmo, constituir uma espécie de consciência de si), necessita e fomenta sua própria destruição e renascimento através da crítica. Toda grande obra quer transcender a si mesma, deseja abrir mão de sua tão necessária autolimitação formal, e continuar sua reflexão alhures. No processo instaurado pela obra de arte, a reflexão está em seu elemento. A obra de arte, portanto, é o Reflexionsmedium, o “medium-de-reflexão” por excelência. E a obra continuará sendo o foco da reflexão, mesmo depois do trabalho crítico, pois este não extrai dela nenhum segredo, nada semelhante a um referente privilegiado que se escondesse por trás da forma e que, uma vez descoberto, a deixaria reduzida à condição de uma casca vazia. Ao contrário, a obra, juntamente com suas críticas, constelase como um medium-de-reflexão cada vez mais forte. A obra passa a ser também suas leituras, as quais suscitam e intensificam o jogo iniciado por ela mesma. 


\section{A reflexão da mercadoria}

É afinado com essa idéia que, por exemplo, o crítico João Alexandre Barbosa afirma, no texto de orelha da tradução brasileira de Charles Baudelaire. Um lírico no auge do capitalismo, que "somente um hipotético e ingênuo leitor de Baudelaire [...] poderia afirmar que aquilo que ele diz de Baudelaire não é aquilo que ele leu de Walter Benjamin em Baudelaire", pois "ler Baudelaire é necessariamente ler a leitura que se fez de Baudelaire e, por isso, é ler Benjamin"s.

"A Paris do Segundo Império em Baudelaire", primeiro dos ensaios benjaminianos dedicados ao poeta durante os anos 1930, é certamente um dos textos mais atípicos da literatura dita filosófica. Benjamin não apenas procura, em largos traços, realizar o ideal de crítica exposto na tese sobre os românticos, como constrói seu próprio texto como uma espécie de alegoria da estrutura da reflexão. Desde as primeiras linhas do ensaio, somos apresentados a uma série de figuras. Algumas são indivíduos históricos, outras, a maioria, tipos. O primeiro a surgir é o tipo do conspirador. "Rememorar a fisionomia [Physionomie $]$ de Baudelaire", diz Benjamin, "significa falar da semelhança que ele exibe com esse tipo político"*. A figura do conspirador, com a qual Baudelaire tem algo em comum, mas com a qual não se identifica de todo, não chega a ser fixada em uma imagem estática, pois logo em seguida temos diante dos olhos o seu desdobramento na figura do provocador, e depois na do delator, em seguida na de Blanqui, e, sem que nos demos conta, estamos às voltas com a figura do trapeiro, o coletor seletivo do lixo urbano. Até o fim do ensaio, não deixarão de surgir figuras como essas, apresentadas por descrições e também textos de época, compondo uma espécie de painel cinético que produz no leitor a sensação algo inebriante e contundente de estar diante do desfile de uma multidão compacta e variada. Todos

${ }^{3}$ A coletânea de ensaios intitulada Charles Baudelaire: ein Lyriker im Zeitalter des Hochkapitalismus se encontra no volume I-2 das Obras completas (Gesammelte Schrifiten), editadas por Rolf Tiedemann e Hermann Schweppenhäuser (Frankfurt: Suhrkamp, 1997). A edição brasileira Charles Baudelaire. Um lírico no auge do capitalismo, da Brasiliense, inclui, além dos três ensaios que fazem parte dessa seção das obras completas, dois capítulos do livro inacabado denominado Projeto das passagens ou Trabalho das passagens (Das Passagen Werk), denominados "O flâneur" e "Jogo e prostituição", que citaremos, adiante, nesta tradução brasileira.

*(Benjamin, Walter. Charles Baudelaire. Um lírico no auge do capitalismo. São Paulo: Brasiliense, 1994: 9) 
são apresentados pelo texto como semelhantes a Baudelaire, mas apenas por um brevíssimo instante.

Durante a leitura, não temos tempo de nos acostumarmos aos traços de algum tipo ou indivíduo histórico que ajudem a recompor a "fisionomia" do poeta, pois os próprios textos da época que Benjamin cita para caracterizá-lo já remetem a uma outra figura. No espaço desse painel, encontramos um número relativamente pequeno de estrofes de poemas de As flores do mal, que surgem aqui e ali, sem que seja delimitado para elas um espaço hierarquicamente superior em relação a outros textos citados. Uma estrofe de soneto pode surgir logo após o trecho de um relato do "chefe de seção na central de polícia"*.

Em uma leitura apressada, poder-se-ia dizer que Benjamin tentava então, nesse painel, "recriar" a época em que Baudelaire viveu, e que, ao fazê-lo, procurava então "explicar" a obra do poeta, enquadrando-a em um esquema de causa e efeito do tipo "tal sociedade, tal poeta". Em outros termos, Benjamin estaria recriando o contexto histórico que teria originado tais textos. As fontes históricas, em sua riqueza e profusão, desvelariam o referente primeiro, que estaria na base da criação poética, a qual, com isso, estaria decifrada.

Uma dessas figuras urbanas da Paris de meados do século XIX deve ser aqui retomada, a fim de mostrar que a hipótese acima nos faz passar bastante longe da intenção do ensaio benjaminiano. Trata-se da famosa figura do flâneur, cujas nuanças ocupam a maior parcela do ensaio. Esse nome identifica um tipo, ou antes, uma prática que esteve em moda no século XIX, a de flanar pelas ruas, testemunhando o fascínio exercido por uma nova experiência: a de poder passear anônimo na multidão e olhar para tudo e para todos com minuciosa curiosidade.

Não se trata, porém, de identificar o indivíduo Charles Baudelaire com a figura histórica do andarilho urbano, pois desse modo estaríamos apenas repetindo o esquema referencial. O ensaio não cansa de negar essa identificação, ao mesmo tempo em que insiste nas várias nuanças da figura desse andarilho observador. O flâneur é uma das faces que o poeta, na leitura de Benjamin, assume provisoriamente. Para utilizarmos aqui um termo caro a Schlegel e Novalis, a estrutura desse personagem chamado Baudelaire é irônica. Mas devemos olhar com particular atenção para a figura do andarilho porque, até certo 
ponto, sua prática é descrita, em primeiro lugar pelo próprio Baudelaire, em termos que podem ser aparentados a uma dinâmica que terminará se revelando reflexiva. Um poema em prosa de Baudelaire intitulado As multidões, e parcialmente citado no ensaio, diz que "O poeta goza o inigualável privilégio de poder ser, conforme queira, ele mesmo ou qualquer outro. Como almas errantes que buscam um corpo, penetra, quando lhe apraz, a personagem de qualquer um. Para o poeta, tudo está aberto e disponível; se alguns espaços lhe parecem fechados, é porque aos seus olhos não valem a pena serem inspecionados"*.

Caso levemos a sério essa possibilidade afirmada com tanto entusiasmo pelo texto do poema, voltamos ao início do ensaio benjaminiano e, em sua releitura, surpreendemos a figura do poeta adentrando como um flâneur o "personagem" do conspirador, do dandy, do trapeiro, do folhetinista. Baudelaire exibiria traços dessas figuras porque teriam lhe parecido interessantes de serem inspecionadas, porque, talvez, mimetizando-as, conseguiria retomar e potenciar o processo de auto-reflexão nelas em curso. E essas figuras, e não outras, interessam-no porque algo na reflexão delas possibilitaria a realização da reflexão dele próprio, Baudelaire. Talvez. Mas devemos lembrar que não é o texto de Baudelaire que realiza efetivamente essas incursões pelas "almas" dos passantes, e sim o texto benjaminiano. É no discurso de seu crítico que Baudelaire se torna mais que nunca um poeta que precisa experimentar certos "personagens", a fim de conhecer as nuanças de sua própria persona poética.

Dito de outro modo, é no ensaio "A Paris do Segundo Império", de Walter Benjamin, que o caráter reflexivo da atitude do flâneur é usado e potenciado. Em última instância, o ensaio faz com que o leitor experimente reflexivamente essa atitude. De um lado, somos levados, como leitores, a adotar a perspectiva cinética do flâneur; do outro, as figuras que vemos nas ruas do ensaio são diversos personagens provisórios assumidos pela figura móvel de Baudelaire.

Voltemos ao trabalho sobre o romantismo e citemos uma longa passagem, que se inicia com mais um trecho de Novalis: "o olho vê apenas olhos - assim também o entendimento apenas entendimento, a alma, almas, a razão, razão, o espírito, espíritos etc. [...]”. Benjamin comenta o fragmento, dizendo:
(Baudelaire, Charles. Pequenos poemas em prosa. Rio de Janeiro: Nova Fron teira, 1983: 52). 
"(Benjamin, Walter. O conceito de crítica de arte no romantismo alemão. Ob. cit: 64).

'(Benjamin, Walter. Charles Baudelaire, um lírico no auge do capitalismo. Ob. cit: 30 ).

"(lbid.: 52-3).
"Apesar disso, a realidade não forma um agregado de mônadas fechadas em si que não podem ter nenhuma relação real umas com as outras. Muito pelo contrário, todas as unidades no real [...] são apenas relativas. Elas estão tão pouco fechadas nelas mesmas e privadas de ligação que, antes, podem, via intensificação de sua reflexão [...], incorporar mais e mais ao próprio autoconhecimento outras essências, outros centros de reflexão"*,

Baudelaire, no ensaio de maturidade de Walter Benjamin, é o nome de um "centro-de-reflexão". Os fenômenos da vida cotidiana da Paris do século XIX, seus personagens até certo ponto marginais, como o flâneur, são incorporados como núcleos de reflexão em que, por sua vez, a reflexão do poeta Baudelaire, uma espécie de personagem reflexivo do ensaio benjaminiano, se fortalece. Essa parece ter sido a aposta do pensador: ao privilegiar a figura do flâneur, ele não reforça uma tese biográfica a respeito do indivíduo autor de As flores do mal, mas consegue trazer para dentro de seu texto crítico uma alegoria da própria reflexão, com a vantagem adicional de se tratar da única figura histórica capaz de transitar entre todos os fenômenos da capital do século XIX.

Nenhum dos fenômenos urbanos perfilados por Benjamin, exceto a mercadoria, possui maior mobilidade que o andarilho. Esta, na verdade, é a razão de ser das ruas e passagens pelas quais transita o flâneur. Tem neste o seu potenciador natural. Se a mercadoria tivesse alma, seria uma alma de flâneur. Esse talvez seja o principal ponto de coesão do ensaio, e é aí que se conecta a reflexão em germe na obra de Baudelaire com a que Walter Benjamin tentava desenvolver nos anos 1930. Esta famosa frase do ensaio serve de umbral para a longa seção dedicada ao andarilho: "Baudelaire sabia como se situava, em verdade, o literato: como flâneur ele se dirige à feira; pensa que é para olhar, mas, na verdade, já é para procurar um comprador"*. Ao olhar, penetra na alma de qualquer um, realizando o que Baudelaire, no poema "As multidões", denomina "santa prostituição da alma" e, mais adiante, a "ebriedade religiosa da cidade grande". "A ebriedade a que se entrega o flâneur", diz Benjamin, "é a da mercadoria em torno da qual brame a corrente dos fregueses"*. Enquanto simples passeador, o flâneur realiza uma mobilidade meramente física. Uma vez, contudo, que seu comportamento 
está profundamente afinado com a vocação da mercadoria para entrar na alma dos passantes, ele realiza uma conexão decisiva com o espírito da cidade moderna. A mercadoria moderna, com seu valor de troca que ignora qualquer particularidade do eventual comprador, adequa-se a qualquer um que possa efetuar sua retirada das vitrines. Enquanto está situada atrás dos vidros, diz a cada um que passa que foi feita para ele. Parafraseando Novalis, através de todos os atributos que observamos na mercadoria, ela nos vê.

$\mathrm{Na}$ leitura intersemiótica que Benjamin faz de Paris, a mercadoria é a verdadeira rainha da circulação. Os habitantes da cidade carregam sua liteira para todos os lados, seja como trabalhadores, seja como consumidores, e mesmo quando se pretendem simples observadores. Mas a mercadoria é muda. Aquele que faz da observação ambulante uma arte, o flâneur, revela-se, no ensaio benjaminiano, destinado a desdobrar a reflexão da mercadoria. Como um virtuose do conhecimento reflexivo tal qual descrito pelos românticos, o flâneur realiza a perfeita identificação com o inanimado. Que seja com a mercadoria, e não com o "fóssil" do fragmento de Novalis, deve-se ao caráter essencialmente histórico dessa reflexão iniciada em Baudelaire e potenciada em Benjamin.

Que o flâneur se descubra nesse destino histórico é algo que só acontece no texto de Walter Benjamin. No de Baudelaire, podemos ler que "o observador é um príncipe que, por toda a parte, passeia o seu incógnito"*. Já em um fragmento do capítulo "O flâneur" de Projeto das passagens, Benjamin diz que "o flâneur é um observador do mercado. [...] ele é, no reino dos consumidores, o emissário do capitalista"*. Em outro fragmento, restam ainda menos vestígios do "príncipe" de que fala Baudelaire. Neste, lemos que "a empatia pela mercadoria é a empatia pelo próprio valor de troca. O flâneur é o virtuose dessa empatia. Leva a passeio o próprio conceito de venalidade. Assim como o grande magazine é seu derradeiro refúgio, assim sua última encarnação é o homem-sanduíche”**.

${ }^{4}$ Em Projeto das passagens, a noção de "fóssil" ganha nova conotação, que a aproximará da conotação de mercadoria. Cf. Buck-Morss, Susan. Dialética do olhar: Walter Benjamin e o Projeto das Passagens. Belo Horizonte / Chapecó: Editora UFMG / Editora Universitária Argos, 2002.
"(Baudelaire, Charles. Oeuvres complètes. Paris: Seuil, 1968: 552, grifo do autor).

"(Benjamin, Walter. Charles Baudelaire, um lírico no auge do capitalismo. Ob. cit.: 199).

(: 227) 
A "empatia", ou seja, viver o mesmo pathos que a mercadoria”, aparenta uma série de tipos enfatizados por Benjamin em seu ensaio. O literato de aluguel que escrevia folhetins para serem publicados com a assinatura de grandes nomes, o "fisiologista" que compõe seus panoramas inofensivos para satisfazer a um mercado crescente de leitores interessados em conhecer o que hoje chamamos "tribos urbanas" e o passeador incógnito que se torna detetive particular são algumas entre tantas nuanças. Baudelaire fez dessa situação uma experiência poética, sua muse vénale, pois lhe pareceu que assim tocava no presente e no futuro da arte. Para potenciá-lo, Benjamin, em seu ensaio, faz o poeta assumir transitoriamente todos esses personagens marginais do mercado.

O literato adentrando a era do valor de exibição da obra de arte pode assim olhar diversas vezes para si próprio. Essa é a principal razão para o ensaio sobre Baudelaire ser construído como um passeio povoado de personagens. Não se trata de um método que Benjamin pudesse aplicar a outras obras. A visita aos diversos personagens mercadológicos da Paris do século XIX, que tinham nos corredores de vitrines das Passagens o seu quartel-general, serve como desdobramento da reflexão de Baudelaire, mas não, por exemplo, da reflexão de Kafka ou de Proust, objetos de análise do pensador alemão em ensaios que encontraram outras estratégias para os seus desdobramentos críticos. A singularidade da obra de Baudelaire, a sua "necessidade de estar aî" foi ressaltada deste modo por Benjamin. É de fato muito difícil esquecer a leitura do crítico quando nos aproximamos, hoje, das páginas do poeta. E vice-versa: ao ler Benjamin, reconhecemos elementos dos autores que ele se dedicou a criticar. Não pretendemos ir mais longe. Tematizar a escrita reflexiva do primeiro ensaio sobre Baudelaire é um modo de compreender a insistência de Walter Benjamin na crítica de textos literários como caminho para intensificação de seu próprio pensamento e de, quem sabe, sugerir um modelo ético/poético para nossas próprias buscas. 


\section{Bernardo Barros Coelho de Oliveira}

Bacharel em Português-Literaturas pela Universidade Federal do Rio de Janeiro. Fez Mestrado e Doutorado em Filosofia, ambos no IFCS/ UFRJ. É professor do Departamento de Filosofia da Universidade Federal do Espírito Santo e do corpo docente do Programa de Pós-Graduação em Letras da mesma instituição. Publicações mais recentes: "Percepção moderna e narrativa dos vestígios. Schlegel, Novalis, Poe e Kafka, um arquipélago benjaminiano" (Murta, Cláudia (org). Mito e arte. Filosofia e suas fronteiras. Vitória: Multiplicidades, 2004), "Leitura irônica do tex to urbano. Apontamentos sobre uma frase de Walter Benjamin à luz de Poe e Auster" (Revista Ipotesi 14. Juiz de Fora: Editora UFJF, 2004). E-mail: bbco@ebrnet.com.br

\section{Resumo}

Análise de alguns aspectos do ensaio "A Paris do Segundo Império em Baudelaire”, de Walter Benjamin, aproximando-o de postulações sobre a crítica literária, oriundas de sua tese sobre Friedrich Schlegel, $O$ conceito de crítica de arte no romantismo alemão. Busca-se mostrar, no trabalho de maturidade sobre o poeta francês, o desdobramento e a culminância de posições formuladas por Benjamin em sua primeira tese, a fim de expor o que se crê ser a concepção benjaminiana de filosofia como atividade crítica, ou seja, potenciação de um jogo reflexivo instaurado pela obra de arte.

\section{Abstract}

Analysis of some aspects of the essay "Paris of the Second Empire in Baudelaire”, by Walter Benjamin, bringing it close to some postulations on literary criticism that have their origin in his thesis on Friedrich Schlegel, The concept of art in the German Romanticism. It is our aim to show, in his late work about the French poet, the unfolding and culmination of positions formulated in his first thesis, in order to reveal what we believe to be the Benjaminian concept of Philosophy as a critical activity, that is, the strengthening of a reflexive game initiated by the work of art.

\section{Résumé}

Analyse de quelques aspects de l'essai "Paris au Second Empire chez Baudelaire”, de Walter Benjamin, les rapportant à des postulations à propos de la critique littéraire provenant de sa thèse sur Friedrich Schlegel, Le concept de critique de l'art dans romantisme allemand. Nous essayerons de montrer, dans le travail de maturité sur le poète français, le déploiement et la culmination de positions formulées par Benjamin dans sa première thèse, pour faire l'exposé de ce que nous prenons pour la conception benjaminienne de la philosophie en tant qu'activité critique, c'est-à-dire la mise en acte d'un jeu de réflexions instauré par l'oeuvre d'art.
Palavras-chave

crítica literária

Walter Benjamin

Charles Baudelaire

Key words

literary criticism

Walter Benjamin

Charles Baudelaire

Mots-clés

critique littéraire

Walter Benjamin

Charles Baudelaire
Recebido em 31/10/2004

Aprovado em 12/01/2005 